\title{
Development and evaluation of a model for secondary evolution educators' professional development needs
}

\author{
William L Romine ${ }^{1 *}$, Ellen Barnett ${ }^{2}$, Patricia J Friedrichsen ${ }^{2}$ and Aaron J Sickel ${ }^{3}$
}

\begin{abstract}
Background: Professional development (PD) efforts have improved acceptance and pedagogical practice related to the theory of evolution in high school biology teachers. However, these teachers express need for more PD related to evolution. It therefore becomes necessary to understand teachers' PD needs prior to structuring PD efforts.
\end{abstract}

Methods: We formulated and validated a model to explain secondary teachers' PD needs using data from a survey of 276 secondary biology teachers who reported teaching evolution.

Results: In addition to reliable subscales, we found that obstacles to teaching evolution, school and community support for evolution instruction, confidence in evolution instruction, and prior coursework in evolution provide a model for PD needs which balances fit and parsimony.

Conclusions: Applications of this model toward the goal of targeting PD efforts are discussed.

Keywords: Evolution; Professional development needs; Teacher education; High school science teaching; Biology; Biology coursework; Confidence; Support; Model development; Evaluation

\section{Background}

The theory of evolution is foundational to the study of biology (American Association for the Advancement of Science 1993; National Research Council 1996), and forms a critical component of scientific literacy for all ages (Brewer and Smith, 2011). Unfortunately, misunderstandings about evolution and its role as a central framework for the biological sciences exist for both high school students (Stallings 1996) and secondary science teachers (Nehm and Sheppard 2004; Nehm et al. 2009), including that humans and dinosaurs coexisted and that evolution does not play a role in antibiotic resistance (Nehm et al. 2009). Anti-evolutionary views also persist, including that the "theory" status of evolution makes it weak, and that creationism should be taught in science classes as an alternative viewpoint (Nehm et al. 2009). Though the need to reform evolution instruction has been heavily documented (AAAS, 1993, Brewer and Smith, 2011; National Research Council 1996), these calls

\footnotetext{
* Correspondence: romine.william@gmail.com

${ }^{1}$ Department of Biological Sciences, Wright State University, 3640 Colonel Glenn Hwy, Dayton, OH 45435, USA

Full list of author information is available at the end of the article
}

have largely been ignored in biology classrooms (Berkman and Plutzer 2011).

Science teacher educators have attempted to address this issue through professional development (PD) opportunities focusing on content knowledge (Nehm and Schonfeld 2007), acceptance (Scharmann et al. 2005), and pedagogical issues (Schrein et al. 2009). The Evolution and the Nature of Science Institute (ENSI) (Beard et al. 2014) comprises a notable online environment designed to help instructors integrate topics in evolution into their classrooms. However, teachers consistently express a need for more PD related to evolution (Griffith and Brem 2004), indicating that they continue to feel unprepared to teach evolution (Asghar et al. 2007). In order to facilitate PD experiences related to evolution instruction that give science teachers maximum benefit in the limited amount of time given each year for $\mathrm{PD}$, it is necessary to understand the facets of PD needs and the factors which influence them.

\section{Review of literature}

Recent research suggests that many science teachers do not teach evolution in accordance with standards or reform efforts. Berkman and Plutzer (2011) surveyed 926 secondary 
biology teachers and found that only $28 \%$ of participants reported teaching evolution in line with the National Science Education Standards (National Research Council 1996), with $60 \%$ cautiously teaching some aspects of evolution and $13 \%$ advocating creationism or intelligent design. Other studies support the assertion that there are science teachers who include some version of creationism into their instruction (Aguillard, 1999; Weld and McNew 1999). Moore's (2007) survey of 107 secondary science teachers revealed that $34 \%$ of participants reported including creationism in the curriculum or not teaching evolution at all. When science teachers do teach evolution, they tend to teach the mechanisms of evolution, such as natural selection, while avoiding large-scale evolutionary trends such as speciation, descent from common ancestry, and human evolution (Aguillard 1999; Schulteis 2010; Tidon and Lewontin 2004; van Dijk 2009). Teachers tend to spend no more than a few weeks on evolution instruction (Berkman et al. 2008; Rutledge and Mitchell, 2002), and are not likely to view evolution as a unifying theme in the curriculum (Berkman et al. 2008).

What explains the general lack of evolution instruction that occurs in high school science classrooms? Three factors have been shown to be associated with teachers' instructional time devoted to teaching evolution in the classroom: 1) content knowledge; 2) acceptance; and 3) knowledge of curriculum standards. Several studies suggest that secondary science teachers possess misunderstandings of evolution (Jimenez-Aleixandre 1994; Rutledge and Mitchell 2002). Nehm and Schonfeld (2007) found that inservice teachers with science degrees demonstrated misconceptions about natural selection similar to those found in K-12 students.

Understanding evolution may be a predictor of instructional time devoted to evolution. Berkman and Plutzer (2011) found that teachers who had taken an evolution course were more likely to teach evolution in line with reform efforts. Using a survey measure with 82 teachers in Oregon, Trani (2004) also found that teachers who demonstrated deeper understandings of evolution were more likely to report that evolution played a major role in the curriculum. In addition to content knowledge, several studies have documented a correlation between acceptance and instructional time. Many teachers openly report that they do not accept evolution or feel internal conflicts about acceptance. For example, Rutledge and Mitchell (2002) reported that $33 \%$ of 552 inservice teachers in Indiana were undecided or did not accept evolution. Teachers often lack key understandings of the nature of science, or feel that their religious beliefs conflict with evolution, thereby leading them to reject evolutionary theory (Abrie 2010; Rutledge and Warden 2000). Teachers who do not accept evolution are less likely to teach it consistently in the classroom (Aguillard 1999; Berkman et al. 2008; Trani 2004). Lastly, research has indicated that when teachers are aware of and possess positive attitudes toward state standards that include evolution, they are more likely to teach it and use the standards as a justification (Donnelly and Boone 2007; Dotger et al. 2010).

In addition to factors associated with the lack of instructional time for teaching evolution, other research has demonstrated two challenges for teachers: 1) reluctance to navigate the controversial aspects of teaching evolution and 2) a lack of pedagogical preparedness to teach evolution. A survey study targeting evolution education in South Africa revealed that teachers had difficulty handling controversy about evolution in their classrooms (Sanders and Ngxola 2009). Cleaves and Toplis (2007) found that experienced teachers in the United Kingdom (UK) reported many incidents of students openly challenging the teaching of evolution, and described their feelings of inadequacy in addressing those challenges. Along with opposition from students, studies in the United States (US) reveal that teachers feel pressure from the community to avoid teaching evolution (Moore and Kraemer 2005; Veal and Kubasko 2003), which may lead them to teach evolution cautiously (Berkman and Plutzer 2011; Goldston and Kyzer 2009). Teachers also report a general lack of preparedness for teaching evolution (Asghar et al. 2007). Of all concerns mentioned by participants in the study by Sanders and Ngxola (2009), 18\% related to concerns about how to teach evolution. Griffith and Brem (2004) found that 15 biology teachers in Arizona desired more access to lesson plans for teaching evolution, accompanied with detailed narratives that explained tips for effective implementation.

Little is known about the effects of PD on teachers' willingness to teach evolution or pedagogical strategies for teaching evolution. When coursework targets a specific aspect of evolution education, improvement with that aspect has been documented. For example, Nehm and Schonfeld (2007) describe an evolution course focused on improving content knowledge and understandings of the nature of science, and reported significant gains in these areas. Another course focused on improving preservice teachers' understandings of the nature of science led to improved abilities to distinguish between the scientific merit of evolution and intelligent design (Scharmann et al. 2005). Our literature review yielded only two studies linking evolution-specific PD to teacher outcomes. Schrein et al. (2009) describes a one-day workshop on teaching evolution for 11 teachers, which focused on a variety of content and pedagogical issues. Most participants reported that they felt more prepared to teach evolution at the conclusion of the workshop, but desired more days for PD. Scharmann (1994) reports significant gains in acceptance and the use of student-centered approaches for inservice teachers after participating in a two-year evolution institute. The purpose of the institute was to improve teachers' content knowledge, understandings of 
the nature of science, acceptance, and access to lesson plans and curricula.

This study addresses a significant gap in the evolution education literature. While the research is clear that many factors are involved with teachers' implementation of evolution instruction, we know little about the relationships between these factors and teachers' self-reported PD needs. Given that many teachers feel unprepared to teach evolution (Asghar et al. 2007) and desire more PD (Griffith and Brem 2004), exploring potential predictors of specific PD needs and elucidating those relationships would be a useful endeavor for designing future evolution courses and PD experiences.

\section{Purpose of the research}

The purpose of this study was exploratory-to find the predictors that best describe the PD needs of biology teachers who teach evolution topics in their high school biology courses. The following questions were addressed:

1. What are the most important predictors for PD needs related to basic pedagogy, contemporary evolution instruction, and standards-based evolution instruction for instructors who report teaching evolution?

2. Can these predictors adequately explain PD needs related to basic pedagogy, contemporary evolution instruction, and standards-based evolution instruction?

3. What is the best model for adequately explaining PD needs which balances fit to the data and parsimony?

The subscale, "basic pedagogy," measured PD needs related to teaching practices that are fundamental to effective didactic evolution instruction. This included responding to opposition to evolution, sequencing of evolution curriculum topics, and writing assessment items. "Contemporary evolution instruction" measured PD needs related to practices which move beyond basic pedagogy, including discussion of current evolution research, use of simulations to teach evolution, and investigations using real data and/or live organisms. "Standards-based evolution instruction" measured teachers' need to link instruction to state and national standards, including the Frameworks for K-12 Science Education and the Next Generation Science Standards, (Schweingruber, et al. 2012; NGSS Lead States, 2013) and Missouri's Course-Level Expectations (Missouri Department of Elementary and Secondary Education, 2008). We refer the reader to the Additional file 1 for a detailed list of these and other survey items related to this study.

\section{Methods}

\section{Study context}

In order to inform the design of a new hybrid content and pedagogy undergraduate course, Teach Evolution, we distributed a survey asking high school biology teachers in Missouri about their evolution teaching practices and their perceived PD needs. At the present time, Missouri has not adopted the Next Generation Science Standards. The current biology standards, known as the Missouri Science Course Level Expectations (CLEs), were revised in 2008. The Missouri Science CLEs earned a grade of "C" in the Thomas B. Fordham Institute's 2000 and 2005 reports comparing state science standards (Gross et al. 2005). In the 2005 report, the evolution portion of the Missouri Science CLEs earned 3 out of a possible 3 points (Gross et al. 2005). However, many of the evolution-related standards are designated as local assessment items and consequently, are not included in the state biology assessment. Therefore, in Missouri, biology teachers are only held accountable for teaching the following evolution concepts: 1) explain the importance of reproduction to the survival of a species; 2) identify examples of adaptations that may have resulted from variations favored by natural selection; and 3) explain how environmental factors can be agents of natural selection (Missouri Department of Elementary and Secondary Education 2008, p. 14).

\section{Instrument development Development of items}

Rigorous research requires the use of valid and reliable instruments; however, no instrument for assessing secondary science teachers' PD needs for teaching evolution exists within the literature. It was therefore necessary to validate subscales for measuring PD needs and potential factors that influence these needs. We developed and administered an assessment in Qualtrics to measure variables that potentially describe teachers' PD needs. This process was led by the third author, a jointly appointed professor in the Division of Biological Sciences and the Department of Learning, Teaching \& Curriculum with 14 years of middle/high school biology teaching experience, and reviewed by another faculty member in the Division of Biological Sciences who teaches an evolution course. In addition, five graduate students, four of whom had high school teaching experience, reviewed the instrument and suggested revisions to increase content validity. The complete instrument is available in the Additional file 1.

\section{Measured and observed variables}

Based on the review of the literature, we included both Likert measured and observed variables on the instrument that could potentially affect the PD needs of teachers. Underlying constructs for Likert measures were extracted through exploratory factor analysis via SPSS 21.0 using the method of principal components with promax rotation. Cronbach's alpha was calculated as an internal consistency measure of precision of item sum scores for each construct. Based on results from factor analysis, the outcome 
of PD could be broken up into three subscales: basic pedagogy ( 8 items, $\left.\alpha_{c}=0.794\right)$, contemporary evolution instruction ( 4 items, $\alpha_{c}=0.633$ ), and standards-based evolution instruction ( 2 items, $\alpha_{c}=0.799$ ). Eight measured predictor variables included perceived knowledge of evolution (13 items, $\left.\alpha_{c}=0.928\right)$, school/community support for teaching evolution ( 4 items, $\alpha_{c}=0.762$ ), perceived obstacles to teaching evolution ( 8 items, $\alpha_{\mathrm{c}}=0.815$ ), lack of resources (4 items, $\alpha_{c}=0.850$ ), familiarity with text (5 items $\alpha_{c}=$ 0.797 ) and internet ( 4 items, $\alpha_{c}=0.770$ ) teaching resources related to evolution instruction, confidence in one's ability to teach evolution (13 items, $\alpha_{c}=0.908$ ), and time spent on evolution topics ( 12 items, $\alpha_{c}=0.827$ ).

We also wished to explore the effect of the teachers' backgrounds on their PD needs. Ten predictor variables were observed through direct reporting, including years in the teaching profession, undergraduate degree (Biology, Biology Education, Unified Science with a Biology emphasis, and Unified Science without a Biology emphasis), teacher certification program (Biology, Unified Science Biology, Unified Science Chemistry, Unified Science Physics, Unified Science Earth Science, and no Biology or Unified Science certification), whether or not the participant has taken an evolution class, path to certification (undergraduate major, master's degree, PRAXIS, or post-baccalaureate certification without a master's degree), involvement with professional organizations (Science Teachers of Missouri, National Science Teachers Association, National Association for Biology Teachers, or None), community environment (Urban, Suburban, and Rural), interference from parents regarding evolution instruction (Parents), and approach to evolution instruction.

\section{Sampling}

The survey was distributed to a database of secondary science teachers in the state of Missouri whose email addresses were obtained from the University of Missouri's Office of Social and Economic Data Analysis. Invitations, with an embedded link to the survey, were sent via email to the teachers. Four reminders were sent, and 531 teachers responded. Only surveys completed by respondents currently or recently teaching general biology who reported teaching evolution were considered in this analysis $(\mathrm{N}=$ 276). This exclusion criterion was essential to the validity of this study since many parts of the survey, such as obstacles to teaching evolution and time spent on evolution topics, would be irrelevant to teachers who do not teach evolution within their biology courses. Participants who completed the survey were given the option of entering a drawing for a $\$ 75$ gift card.

\section{Sample characteristics}

The teachers' experience ranged from 0 to 41 years with a mean value of 11 . Most (68\%) held an undergraduate degree in either biology or biology education; 20\% had a unified science degree with a biology emphasis, and the remainder of the respondents had a degree that was unified science without a biology emphasis or some other undergraduate degree. Fifty-eight percent of the teachers had taken an evolution class. Eighty-one percent of the respondents had a master's degree, and of those, $43 \%$ had completed a master's degree in education; $14 \%$ were in biology or a biology related field, and all others were in administration or some other area. The teachers pursued various paths to certification. Half received certification as part of their undergraduate preparation. One-fourth earned certification with their master's degree, and the remaining fourth were certified by passing the PRAXIS exam in a postbaccalaureate teacher preparation program. The majority of respondents (60\%) were not members of a professional science education organization at the state or national level. Fourteen percent were members of the state science teacher organization. One-third were members of the National Science Teachers' Association (NSTA) and four percent were members of the National Association of Biology Teachers (NABT). Forty-three percent of the teachers reported teaching in rural schools; $44 \%$ taught in suburban schools, and 13\% taught in urban schools.

\section{Model selection \\ Stepwise regression}

Multiple linear regression via the forward-stepwise algorithm $(\alpha=0.05)$ with SPSS 21.0 was used to reduce the large pool of predictors to a few that were most important in describing needs related to the three dimensions of PD (basic pedagogy, contemporary evolution instruction, and standards-based evolution instruction). The forwardstepwise algorithm contains both a forward and backward component. In the forward component, the addition of each potential predictor to the null model is tried. If none of the predictors increases the explained variance in PD needs with respect to the null model (measured with the $r$-square statistic) at a significance of $\alpha=0.05$ (measured by the partial F statistic), the algorithm stops. Otherwise, the predictor that most significantly improves the r-square of the regression is added to the model. This process continues until no more predictors significantly improve the variance explained by the current model. The forwardstepwise algorithm takes the forward process further, however, by adding a backwards step between each forward step; an attempt is made to remove each variable from the model in a leave-one-out fashion. If removing a variable reduces the $r$-square at $\alpha=0.10$, then it is retained in the present model; otherwise, it is removed. After this backwards step, the next forward step proceeds. Since the order in which variables are entered can impact their effect on the model r-square, alternating forward and backward steps reduces bias in model selection. 


\section{Structural equation modeling}

Unlike stepwise linear regression, structural equation modeling (SEM) takes a holistic confirmatory modeling approach, meaning that the measurement (from factor analysis) and structural (from regression) models are specified beforehand and tested simultaneously. Using predictors that were significant in the stepwise regression and hypothesized item-construct relationships from principal components factor analyses, a measurement model nested within a structural model was specified. While separate stepwise linear regressions are effective in finding the most causative predictors for a specific type of PD need, this procedure is limited in that it does not account for relationships between the dependent variables and error covariance between items. Unlike ordinary regression, SEM allows testing of relationships between the underlying predictor and outcome variables simultaneously, taking into account the covariance between these variables and their measurement errors during the calculation and evaluation of path coefficients (Bollen 1989). SEM has an additional advantage in that it allows nesting of the measurement model (the model relating survey items to measured variables) within the structural model (the model which links the measured and observed variables). In this way, the parameters for the multiple factor analyses and regressions can be quantified within a single model instead of as multiple unrelated procedures.

\section{Model specification and testing}

LISREL 8.80 was used to solve path coefficients for the measurement and structural models via the full information maximum likelihood (FIML) procedure. The measurement model links individual survey items to their underlying constructs while the structural model quantifies the relationships between these constructs. In defining the measurement model, the measured variables were expressed as predictors for item responses. Hence, the measurement model consists of one measurement equation for each item, and loading of the item onto measured variable(s) is expressed through the regression slope(s). In addition, item error variances and error covariances between related items were set to vary freely. An observed variable was specified in the model by fixing the regression slope to 1 and the measurement error to 0 .

In the structural model, predictors found to be significant in the forward-stepwise models (exogenous variables) were regressed onto the three measured PD need outcomes (endogenous variables). The root mean square error of approximation (RMSEA) was used as the omnibus test for fit of the structural model with the data. An RMSEA at or below 0.06 is indicative of acceptable fit ( $\mathrm{Hu}$ and Bentler 1995). The z-test $(\alpha=0.05)$ was used to test the null hypothesis that individual path coefficients are zero for both the measurement and structural models.

\section{Model comparison}

Since stepwise regressions have a tendency for overfitting (Steyerberg et al. 1999), we sought to compare the full structural model derived from stepwise regression with simpler alternative models in search of parsimony. In comparison of nested models, the model including all variables and links specified by the stepwise regressions was treated as the full model. Independent variables were removed in a leave-one-out fashion in order to find the relative significance of each predictor as a descriptor of PD needs when all other variables were included. The chisquare was used as a test for reduction of fit upon removal of a variable, and was evaluated at $\alpha=0.05$ significance. Akaike's Information Criterion (AIC) was used as an additional indicator of comparative model fit. A function of the goodness of fit of the model and the number of parameters, information criteria such as the AIC have been shown to reliably indicate the best-specified model out of two or more candidate models (Burnham and Anderson 2004). The model with the best fit for the number of variables is indicated by the minimum AIC value.

\section{Results}

\section{Regression models}

Five variables were found to be significant predictors for PD needs (Table 1) for teachers who report teaching evolution. Two predictors, perceived obstacles to teaching evolution (ObTch) and perceived knowledge (Knowl), were found to adequately account for the variance in PD needs related to basic pedagogy $[F(2,245)=14.22, p<<$ $0.01]$. In addition to perceived obstacles to teaching evolution and perceived knowledge, the predictors of supportive

Table 1 Main effects linear regression models derived from the forward-stepwise method

\begin{tabular}{llllll}
\hline Outcome & Predictor & B & SE & $\mathbf{t}$ & $\mathbf{p}$ \\
\hline Basic & & & & & \\
& Intercept & 11.18 & 1.65 & 6.79 & 0.00 \\
& ObTch & 0.26 & 0.05 & 5.17 & 0.00 \\
& Knowl & 0.07 & 0.03 & 2.27 & 0.02 \\
Contemporary & & & & & \\
& Intercept & 6.41 & 0.93 & 6.86 & 0.00 \\
& Knowl & 0.04 & 0.01 & 2.81 & 0.01 \\
& ObTch & 0.08 & 0.02 & 3.16 & 0.00 \\
& Support & 0.13 & 0.05 & 2.33 & 0.02 \\
& EvolCls & 0.38 & 0.17 & 2.22 & 0.03 \\
Standards & & & & & \\
& Intercept & 2.22 & 0.65 & 3.42 & 0.00 \\
& ObTch & 0.08 & 0.02 & 3.79 & 0.00 \\
& Confid & 0.04 & 0.02 & 2.56 & 0.01 \\
& EvolCls & -0.31 & 0.15 & -2.03 & 0.04 \\
\hline
\end{tabular}


community environment (Support) and having taken an evolution class (EvolCls) were found to be significant for PD needs related to contemporary evolution instruction $[F(4,246)=6.55, p<<0.01]$. Perceived obstacles to teaching evolution, having taken an evolution class, and confidence in ability to teach evolution (Confid) were found to be significant for PD needs related to standards-based evolution instruction $[F(3,248)=6.63, p<<0.01]$. All variables had significant positive relationships to PD needs with the exception of having taken an evolution class, which showed a negative relationship to standards-related PD needs.

\section{Structural equation model}

The structural equation model combining the hypothesized item-factor relationships from the factor analyses and predictor-outcome relationships derived from the previous univariate regressions fit the data with an RMSEA of 0.047, which is well below the criterion of good fit of 0.06 proposed by $\mathrm{Hu}$ and Bentler (1995). In the measurement model for PD needs (Table 2), all parameters, with the exception of the error variance of Q5.5_13, were significant at $\alpha<<0.01$. The relationship between item responses and their hypothesized measured predictor variables (supportive community, perceived knowledge, confidence in instruction, and perceived obstacles to teaching evolution) were significant (Table 3). However, fit of the structural model was improved by taking into account the fact that certain items measuring obstacles to getting support also measured other constructs. For example, Item Q6.2_1, in addition to its expected relationship with obstacles to getting support, also showed a comparatively small but significant positive relationship with perceived knowledge. In addition, Items Q6.2_2 and Q6.2_3 measured lack of

Table 2 Measurement model for PD needs

\begin{tabular}{lllll}
\hline Item & Basic & Contemporary & Standards & Error Variance \\
\hline Q5.5_1 & & 0.27 & & 0.18 \\
Q5.5_2 & & 0.35 & 0.15 \\
Q5.5_3 & & 0.16 & 0.27 \\
Q5.5_4 & 0.15 & & 0.35 \\
Q5.5_5 & & 0.20 & 0.26 \\
Q5.5_6 & 0.28 & & 0.40 \\
Q5.5_7 & 0.47 & & 0.23 \\
Q5.5_8 & 0.35 & & 0.20 \\
Q5.5_9 & 0.36 & & 0.29 \\
Q5.5_10 & 0.49 & & 0.24 \\
Q5.5_11 & 0.51 & & 0.47 & 0.24 \\
Q5.5_12 & & & 0.58 & $0.13^{\mathrm{a}}$ \\
Q5.5_13 & & & & 0.25 \\
Q5.5_14 & 0.38 & & & \\
\hline
\end{tabular}

${ }^{a}$ Not significant $(a=0.05)$. All other parameters significant $(a<<0.01)$.
Table 3 Measurement model for independent variables

\begin{tabular}{|c|c|c|c|c|c|}
\hline Item & Support & Knowl & Confid & ObTch & Error variance \\
\hline Q3.5_1 & 0.35 & & & & 0.17 \\
\hline Q3.5_2 & 0.47 & & & & 0.09 \\
\hline Q3.5_3 & 0.47 & & & & 0.21 \\
\hline Q3.5_4 & 0.13 & & & & 0.18 \\
\hline Q5.1_1 & & 0.30 & & & 0.13 \\
\hline Q5.1_2 & & 0.33 & & & 0.25 \\
\hline Q5.1_3 & & 0.42 & & & 0.24 \\
\hline Q5.1_4 & & 0.49 & & & 0.32 \\
\hline Q5.1_5 & & 0.48 & & & 0.23 \\
\hline Q5.1_6 & & 0.48 & & & 0.26 \\
\hline Q5.1_7 & & 0.50 & & & 0.25 \\
\hline Q5.1_8 & & 0.44 & & & 0.37 \\
\hline Q5.1_9 & & 0.55 & & & 0.21 \\
\hline Q5.1_10 & & 0.45 & & & 0.18 \\
\hline Q5.1_11 & & 0.49 & & & 0.16 \\
\hline Q5.1_12 & & 0.44 & & & 0.26 \\
\hline Q5.1_13 & & 0.38 & & & 0.20 \\
\hline Q5.3_1 & & & 0.10 & & 0.04 \\
\hline Q5.3_2 & & & 0.32 & & 0.36 \\
\hline Q5.3_3 & & & 0.36 & & 0.27 \\
\hline Q5.3_4 & & & 0.44 & & 0.24 \\
\hline Q5.3_5 & & & 0.45 & & 0.17 \\
\hline Q5.3_6 & & & 0.33 & & 0.24 \\
\hline Q5.3_7 & & & 0.44 & & 0.21 \\
\hline Q5.3_8 & & & 0.34 & & 0.35 \\
\hline Q5.3_9 & & & 0.45 & & 0.17 \\
\hline Q5.3_10 & & & 0.37 & & 0.14 \\
\hline Q5.3_11 & & & 0.31 & & 0.15 \\
\hline Q5.3_12 & & & 0.34 & & 0.22 \\
\hline Q5.3_13 & & & 0.26 & & 0.13 \\
\hline Q6.2_1 & & 0.18 & & 0.41 & 0.52 \\
\hline Q6.2_2 & & $-0.09^{\mathrm{a}}$ & -0.20 & 0.23 & 0.34 \\
\hline Q6.2_3 & & $-0.09^{a}$ & -0.21 & 0.18 & 0.24 \\
\hline Q6.2_6 & & & 0.07 & 0.26 & 0.15 \\
\hline Q6.2_7 & & & & 0.64 & 0.25 \\
\hline Q6.2_8 & & & & 0.57 & 0.38 \\
\hline Q6.2_9 & & & & 0.51 & 0.33 \\
\hline
\end{tabular}

${ }^{a}$ Not significant $(a=0.05)$. All other parameters significant $(a<<0.01)$.

confidence (indicated by their significant negative loadings on confidence) in addition to perceived obstacles to teaching evolution. Item Q6.2_6, in addition to its expected relationship with perceived obstacles to teaching evolution, also had a comparatively small but significant positive relationship with confidence. Having taken an evolution class was defined to have a perfect relationship and no error 
variance with respect to its underlying construct since it was directly reported, and thus is not included in Table 3.

\section{Selection of the best model}

Given that the full structural model fit the data well, we attempted to simplify the model. We found that removal of perceived obstacles to teaching evolution $\left(x^{2}=32.68\right.$, $\mathrm{df}=3, \mathrm{p}<<0.001, \mathrm{AIC}=2301.03)$, supportive community $\left(X^{2}=6.15, \mathrm{df}=1, \mathrm{p}=0.013, \mathrm{AIC}=2282.19\right)$, having taken an evolution class $\left(\chi^{2}=18.1, \mathrm{df}=2, \mathrm{p}<<0.001\right.$, $\mathrm{AIC}=2292.14)$, and confidence in instruction $\left(\chi^{2}=8.07\right.$, $\mathrm{df}=1, \mathrm{p}=0.005$, AIC $=2284.11$ ) led to a significant reduction in fit at the $\alpha=0.05$ level, and a subsequent increase in the AIC above the full model value of 2278.04 indicating their importance in the model. However, removal of perceived knowledge caused no significant reduction in fit $\left(x^{2}=3.57, \mathrm{df}=2, \mathrm{p}=0.17\right.$, $\left.\mathrm{AIC}=2277.61\right)$, and reduced the AIC, indicating improved fit with respect to the number of model parameters. Since the removal of supportive community did not significantly reduce the fit of the full model at the $\alpha=0.01$ level, we attempted to remove this in addition to perceived knowledge to further simplify the model. This led to a significant reduction in fit and an increase in the $\mathrm{AIC}\left(\mathrm{X}^{2}=\right.$ 7.07, $\mathrm{df}=1, \mathrm{p}=0.008, \mathrm{AIC}=2282.68)$, indicating that the best model contains all of the original predictors with the exception of perceived knowledge.

As previously indicated in the univariate regression models, one or more predictors were significantly related to each of the respective PD needs (Table 4). After removal of perceived knowledge, perceived obstacles to teaching evolution was the sole significant predictor for PD needs related to basic pedagogy. Significant positive predictors for PD needs related to contemporary evolution instruction included having a supportive community environment and having taken an evolution class. Having taken an evolution class had a negative relationship with PD needs related to standards-based teaching,

\section{Table 4 The best-fit structural model for PD needs}

\begin{tabular}{lllll}
\hline Teaching type & Predictor & $\mathbf{B}_{\text {path }}$ & $\mathbf{S E}_{\mathbf{B}}$ & $\mathbf{Z}$ \\
\hline Basic & ObTch & 0.34 & 0.11 & $3.09^{* *}$ \\
& Error & 0.79 & 0.41 & 1.93 \\
Contemporary & ObTch & 0.21 & 0.11 & 1.91 \\
& Support & 0.23 & 0.11 & $2.09^{*}$ \\
& EvolClass & 0.41 & 0.17 & $2.41^{*}$ \\
Standards & Error & 0.96 & 0.28 & $3.43^{* *}$ \\
& ObTch & 0.32 & 0.094 & $3.40^{* *}$ \\
& Confidence & 0.14 & 0.078 & 1.80 \\
& EvolClass & -0.33 & 0.15 & $-2.20^{*}$ \\
& Error & 0.92 & 0.24 & $3.83^{* *}$ \\
\hline
\end{tabular}

${ }^{*} p<0.05,{ }^{* *} p<0.01$ and perceived obstacles to teaching evolution had a significant positive relationship. The relationships between perceived obstacles to teaching evolution and PD needs related to contemporary evolution instruction, and between confidence in instruction and PD needs related to standards-based evolution instruction were both positive, but not significant at the $\alpha=0.05$ level. Significant error terms for PD related to inquiry and standards reflect systematic trends in the error due to measurement error or important causes not measured in this study.

\section{Discussion}

In this study, we sought to identify a simple and effective model for understanding secondary biology teachers' PD needs related to evolution instruction. In the interest of response validity, we chose to exclude teachers who reported leaving evolution out of their biology instruction since questions related to confidence in teaching evolution topics, perceived support for teaching evolution, and PD needs related to evolution instruction would be largely irrelevant to these teachers. That $52 \%$ of all respondents in this study reported teaching evolution is in good agreement with the value of $60 \%$ obtained by Berkmann and Plutzer (2011).

Toward the goal of helping biology teachers integrate evolution into their classrooms, it is interesting that only four of the 18 potential predictors were shown to be important in describing PD needs for these teachers (Figure 1). While perceived knowledge of evolution topics was significant in the individual regression models, it fell out of the structural model. This makes sense given that asking teachers to rate their familiarity with certain topics is more a measure of confidence than actual knowledge and can therefore be accounted for through the predictors of confidence in instruction and perceived obstacles to teaching evolution. Two of the significant predictors related to support for teaching evolution: community support for teaching evolution, which addresses external sources of support, and perceived obstacles to teaching evolution. Previous findings indicate that biology teachers around the world have difficulty navigating the controversy that permeates evolution instruction (Sanders and Ngxola 2009; Cleaves and Toplis 2007; Moore and Kraemer 2005). Our findings build upon this, showing that teachers who perceive these obstacles feel greater need for PD related to all aspects of evolution instruction. The positive role of perceived support in PD needs related to contemporary evolution instruction adds extra complexity, indicating that teachers who get more encouragement from school, community, and colleagues are more likely to express desire for PD that helps them move past basic pedagogy. This relationship makes sense in light of research on teacher development (i.e. Fuller 1969). A supportive school and community environment will help teachers transition from novice stages 


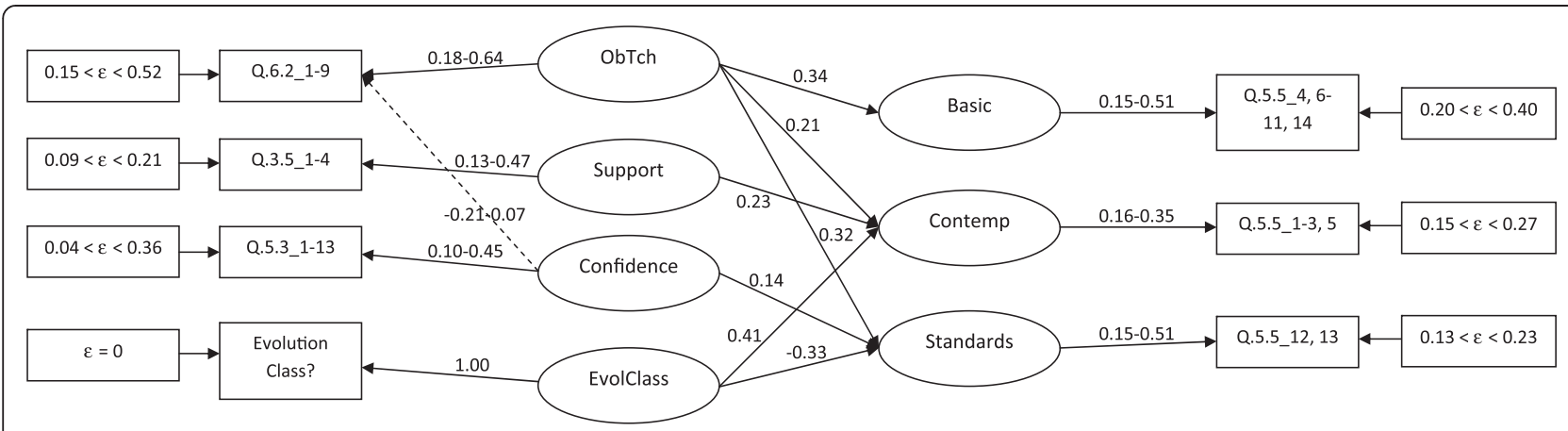

Figure 1 Measurement and structural models for PD needs related to evolution instruction.

which focus on the need for survival and control to more advanced stages which focus on finding ways to optimize student learning (Fuller 1969). A non-significant positive relationship indicates that PD related to contemporary teaching strategies may be helpful for teachers who struggle to navigate controversy about evolution in their classrooms and schools. However, obstacles are much more strongly associated with PD needs related to basic pedagogy and standards-based teaching. Despite numerous calls to move toward student-centered instruction, basic pedagogical practices must be mastered before a teacher can be expected to effectively implement more advanced pedagogies (Berliner 1988). It follows that biology teachers in nonsupportive environments will likely achieve greatest benefit from programs focusing on building proficiency with teacher-centered strategies which may help improve perceived control over classroom instruction. In addition, emphasis on state and national standards may help struggling teachers address criticism through citation of standards to justify why evolution needs to be covered in the biology classroom (Donnelly and Boone 2007; Dotger, et al. 2010).

Confidence in ability to teach evolution was positively associated with PD needs related to standards-based teaching, indicating that teachers who feel more confident in their ability to effectively teach evolution topics in biology classes may show preference for PD focusing on biology standards as opposed to basic and contemporary pedagogical strategies. This makes sense given that standards tend to change much more quickly than ideas of teaching best practice. While AIC and chi-square model comparison tests show that confidence is an important part of the model, its lack of significance at the $\alpha=0.05$ level indicates its lack of importance in comparison with the factors of community support and background with evolution coursework.

Previous studies indicate that taking an evolution course increases the likelihood of teaching evolution in line with reform efforts (Berkman and Plutzer 2011). Our data indicate that prior coursework related to evolution also plays an important role in perceived PD needs. Teachers who had previously taken an evolution course felt a greater need to focus on contemporary teaching strategies and reduced need for focus on state and national standards related to evolution. It is interesting that this simple piece of information can be used to inform design of well-targeted PD opportunities for biology teachers. The finding that taking an evolution course increases perceived need for improving contemporary teaching strategies makes sense in light of the documented importance of deep understanding on decisions to implement reform-based teaching strategies (Berkman and Plutzer 2011; Trani 2004). However, the negative influence on perceived need for PD focused on standards is more difficult to explain. Since standards directly relate to content that should be taught, it is possible that teachers with more content knowledge feel familiar with evolution content that needs to be taught, precluding the perceived need to consult state and national standards. These teachers may also have stronger opinions regarding what should be taught in their biology classes, and thus feel less need to consult standards for justification. In a study of high school Biology teachers in Ohio, Borgerding (2012) found that teachers who held more positive views of the state standards tended to cover a greater variety of evolution topics in their classrooms. Since taking an evolution class may lead to more positive views of evolution and the importance of standards, it is possible that these teachers will be more likely to consult, study, and attempt to teach to existing standards themselves without need for PD. Further research similar to Borgerding (2012) will be needed to directly test assertions regarding the complex interactions between biology teachers, their instruction, and education standards related to evolution.

In order to fully understand evolution teachers' PD needs, it is also useful to look at certain variables that did not contribute to the model. It may seem surprising that observed variables related to evolution teachers' certification backgrounds including educational level and path to certification, school size, and type of community, were shown to be unimportant for describing PD needs. It may similarly seem surprising that measured constructs related to familiarity with 
teaching resources did not contribute to the model. This should not be taken to mean that PD for biology teachers should not address how to find and use teaching resources or be tailored to specific school and community environments; indeed, these comprise major goals of PD efforts such as ENSI. Rather, it implies that variance related to PD needs that is explained by these variables is already subsumed by the four core predictors in the model. For example, it is reasonable to expect that familiarity with teaching materials would be positively associated with confidence in teaching evolution material and negatively associated with obstacles to finding a supportive teaching environment. Thus, we propose that PD which increases teachers' familiarity with available evolution teaching resources would also increase teachers' confidence in their instruction and help them overcome social obstacles such as opposition from parents, administrators, and students.

While our structural model brings simplicity and unity to our understanding of PD needs for biology teachers who teach evolution, it also illustrates the complexity of the topic. Significant error variances for many of the variables indicate that there is much left unexplained. Where does the unexplained variance lie? Some of the unexplained variance can be attributed to measurement error, which is reflected by Cronbach's alpha reliability measures below unity. However, significant error trends for contemporary and standards-based learning may indicate that there are other potentially important predictors that were unmeasured in this study and therefore unaccounted for by the model. For example, an important limitation of this study is that we did not ask teachers to specifically indicate whether or not they personally accept the theory of evolution; rather we only asked them if this was an obstacle they faced. Similarly, we did not ask teachers to indicate how they identify with anti-evolutionary ideas such as those associated with creationism. This was likely partially accounted for through the screening criterion we imposed given that acceptance of evolution influences personal decisions regarding whether or not to include it in the biology curriculum (Abrie 2010). However, since curricular decisions are often made at the state, district, school, and department levels, it would be incorrect to assume that the teacher has sole discretion over curricular content. Given that a biology teacher's acceptance of evolution influences how he/she chooses to integrate it into the curriculum (Abrie 2010), it is reasonable to expect that degree of acceptance of evolution and identification with creationist ideas would also influence PD needs among those who teach evolution. Exploration of facets of evolution acceptance and how they link to PD needs will be left to future research.

\section{Conclusion}

Findings from prior research indicate that many factors play a role in high school teachers' decisions to implement evolution instruction in the biology classroom, and multiple studies have documented the effectiveness of $\mathrm{PD}$ experiences in helping teachers move toward reform-based practice in the teaching of evolution. However, these teachers continue to express need for more PD. Little work has been done toward understanding factors that influence the PD needs of biology teachers who teach evolution. In this study, we undertook a systematic evaluation of potential factors influencing these teachers' perceived PD needs and presented a simple model that can be used to direct PD efforts. The model shows that factors related to support, confidence, and prior evolution coursework play an important role in the types of PD that biology teachers need. Presentation of such a model lends the assertion that a key to implementation of successful PD programs must begin with an attempt to understand participants' prior experience and perceptions about the topic of evolution and its implementation in the biology classroom. We hope that findings from this study will be used to inform these efforts, and ultimately lead the way to more effective PD programs aimed at helping teachers of evolution improve their instruction.

\section{Additional file}

Additional file 1: Survey of Professional Development Needs for Evolution Instructors.

\section{Competing interests}

The authors declare that they have no competing interests.

\section{Authors' contributions}

WR carried out data analysis and drafted the background, methods, results, and discussion sections with the assistance of EB. EB and PF designed the survey, used it to collect data from evolution educators, and contributed to the background, methods, and discussion sections. AS drafted the review of literature. All authors read and approved the final manuscript.

\section{Acknowledgements}

This material is based upon work supported by the National Science Foundation Transforming Undergraduate Education in Science (TUES) program under Grant 114062. Any opinions, findings, and conclusions or recommendations expressed in this material are those of the author(s) and do not necessarily reflect the views of the National Science Foundation.

\section{Author details}

${ }^{1}$ Department of Biological Sciences, Wright State University, 3640 Colonel Glenn Hwy, Dayton, OH 45435, USA. ${ }^{2}$ Science Education Center, University of Missouri, 321 Townsend Hall, Columbia, MO 65211, USA. ${ }^{3}$ School of Education, University of Western Sydney, Locked Bag 1797, Penrith, NSW 2751, Australia

Received: 20 May 2014 Accepted: 16 October 2014

Published online: 05 November 2014

\section{References}

Abrie, AL. (2010). Student teachers' attitudes toward and willingness to teach evolution in a changing South African environment. Journal of Biological Education, 44, 102-107.

Aguillard, D. (1999). Evolution education in Louisiana public schools: a decade following Edwards v Aguillard. American Biology Teacher, 61, 182-188. 
American Association for the Advancement of Science. (1993). Benchmarks for science literacy. Oxford University Press.

Asghar, A, Wiles, JR, \& Alters, B. (2007). Canadian pre-service elementary teachers' conceptions of biological evolution and evolution education. McGill Journal of Education, 42, 189-209.

Beard, J, Nelson, C, \& Nickels, M. (2014). Evolution and the Nature of Science Institutes (ENSI). Available online at http://www.indiana.edu/ ensiweb/home.html.

Berkman, MB, \& Plutzer, E. (2011). Defending evolution in the courtroom, but not in the classroom. Science, 331, 404-405.

Berkman, MB, Pacheco, JS, \& Plutzer, E. (2008). Evolution and creationism in America's classrooms: a national portrait. PLoS Biology, 6, 920-924.

Berliner, DC. (1988). The Development of Expertise in Pedagogy. One Dupont Circle, Suite 610, Washington, DC: AACTE Publications. 20036-2412.

Bollen, KA. (1989). Structural Equation Modeling With Latent Variables (2nd ed.). New York: Wiley.

Borgerding, L. (2012). Ohio state biology teachers' views of state standard for evolution: impacts on practice. Science Educator, 21(1), 19-28.

Brewer, CA, \& Smith, D. (2011). Vision and change in undergraduate biology education: a call to action. Washington, DC: American Association for the Advancement of Science.

Burnham, A, \& Anderson, D. (2004). Multimodel inference: understanding AIC and BIC in model selection. Sociological Methods \& Research, 33(2), 261-304.

Cleaves, A, \& Toplis, R. (2007). In the shadow of intelligent design: the teaching of evolution. Journal of Biological Education, 42, 30-35.

Donnelly, LA, \& Boone, WJ. (2007). Biology teachers' attitudes toward and use of Indiana's evolution standards. Journal of Research in Science Teaching, 44, 236-257.

Dotger, S, Dotger, BH, \& Tillotson, J. (2010). Examining how preservice science teachers navigate simulated parent-teacher conversations on evolution and intelligent design. Science Education, 94, 552-570.

Fuller, F. (1969). Concerns of teachers: a developmental conceptualization. American Educational Research Journal, 6, 207-226.

Goldston, MJ, \& Kyzer, P. (2009). Teaching evolution: narratives with a view from three southern biology teachers in the USA. Journal of Research in Science Teaching, 46, 762-790

Griffith, JA, \& Brem, SK. (2004). Teaching evolutionary biology: pressures, stress, and coping. Journal of Research in Science Teaching, 41, 791-809.

Gross, PR, Goodenough, U, Hack, S, Lerner, LS, Schwartz, M, \& Schwartz, R. (2005). The State of State Science Standards. Washington, DC: Thomas B Fordham Institute.

Hu, LT, \& Bentler, PM. (1995). Evaluating Model Fit. In RH Hoyle (Ed.), Structural Equation Modeling: Concepts, Issues, and Applications. Thousand Oaks: Sage.

Jimenez-Aleixandre, MP. (1994). Teaching evolution and natural selection: a look at textbooks and teachers. Journal of Research in Science Teaching, 31, 519-535.

Missouri Department of Elementary and Secondary Education. (2008). Science Course Level Expectations: A framework for instruction and assessment. Available online at https://dese.mo.gov/sites/default/files/cle-biology-science.pdf.

Moore, R. (2007). The differing perceptions of teachers \& students regarding teachers' emphasis on evolution in high school biology classrooms. American Biology Teacher, 69, 268-271.

Moore, R, \& Kraemer, K. (2005). The teaching of evolution and creationism in Minnesota. American Biology Teacher, 67, 457-466.

National Research Council. (1996). National Science Education Standards. Washington, DC: National Academy Press.

Nehm, RH, \& Schonfeld, IS. (2007). Does increasing biology teacher knowledge of evolution and the nature of science lead to greater preference for the teaching of evolution in schools? Journal of Science Teacher Education, 18, 699-723.

Nehm, RH, \& Sheppard, K. (2004). A comparative study of evolutionary understanding and advocacy for teaching evolution in pre-certified biology and other science teachers. In Annual meeting of the National Association for Research in Science Teaching. Vancouver, BC, Canada.

Nehm, RH, Kim, SY, \& Sheppard, K. (2009). Academic preparation in biology and advocacy for teaching evolution: biology versus non-biology teachers. Science Education, 93(6), 1122-1146.

NGSS Lead States. (2013). Next Generation Science Standards: For States, By States. Achieve, Inc. on behalf of the twenty-six states and partners that collaborated on the NGSS.

Rutledge, ML, \& Mitchell, MA. (2002). Knowledge structure, acceptance, \& teaching of evolution. The American Biology Teacher, 64, 21-28.
Rutledge, ML, \& Warden, MA. (2000). Evolutionary theory, the nature of science \& high school biology teachers: Critical relationships. The American Biology Teacher, 62, 23-31.

Sanders, M, \& Ngxola, N. (2009). Identifying teachers' concerns about teaching evolution. Journal of Biological Education, 43, 121-128.

Scharmann, LC. (1994). Teaching evolution: the influence of peer teachers' instructional modeling. Journal of Science Teacher Education, 5, 66-76.

Scharmann, LC, Smith, MU, James, MC, \& Jensen, M. (2005). Explicit reflective nature of science instruction: evolution, intelligent design, and umbrellaology. Journal of Science Teacher Education, 16, 27-41.

Schrein, CM, Lynch, JM, Brem, SK, Marchant, GE, Schedler, KK, Spencer, MA, Kazilek, CJ, \& Coulombe, MG. (2009). Preparing teachers to prepare students for post-secondary science: Observations from a workshop about evolution in the classroom. Journal of Effective Teaching, 9, 69-80.

Schulteis, MW. (2010). Education's missing link: How private school teachers approach evolution. The American Biology Teacher, 72, 91-94.

Schweingruber, H, Keller, T, \& Quinn, H. (2012). A Framework for K-12 Science Education: Practices, Crosscutting Concepts, and Core Ideas. National Academies Press.

Stallings, MA. (1996). The Influence of a Diversified Instructional Strategy on High School Biology Students. Unpublished Doctoral Dissertation. Manhattan: Kansas State University.

Steyerberg, E, Eijkemans, M, \& Habbema, D. (1999). Stepwise selection in small data sets: a simulation study of bias in logistic regression analysis. Journal of Clinical Epidemiology, 52(10), 935-942.

Tidon, R, \& Lewontin, RC. (2004). Teaching evolutionary biology. Genetics and Molecular Biology, 27, 124-131.

Trani, R. (2004). I won't teach evolution; it's against my religion: and now for the rest of the story. The American Biology Teacher, 66, 419-427.

van Dijk, EM. (2009). Teachers' views on understanding evolutionary theory: a PCK-study in the framework of the ERTE-model. Teaching and Teacher Education, 25, 259-267.

Veal, WR, \& Kubasko, DS, Jr. (2003). Biology and geology teachers' domain-specific pedagogical content knowledge of evolution. Journal of Curriculum and Supervision, 18, 334-352.

Weld, J, \& McNew, JC. (1999). Attitudes toward evolution. The Science Teacher, $66,27-31$.

doi:10.1186/s12052-014-0027-y

Cite this article as: Romine et al: Development and evaluation of a model for secondary evolution educators' professional development needs. Evolution: Education and Outreach 2014 7:27.

\section{Submit your manuscript to a SpringerOpen ${ }^{\circ}$ journal and benefit from:}

- Convenient online submission

Rigorous peer review

- Immediate publication on acceptance

- Open access: articles freely available online

- High visibility within the field

- Retaining the copyright to your article

Submit your next manuscript at $>$ springeropen.com 